\title{
Ethical considerations in hibernation research
}

\author{
Tulasi R. Jinka and Lawrence K. Duffy \\ Department of Chemistry and Biochemistry, Alaska Basic Neuroscience Program and Institute of \\ Arctic Biology, University of Alaska Fairbanks, Fairbanks, AK
}

\begin{abstract}
Ethical research practices are a key component of scientific integrity and of public support for research. Hibernation research presents specific ethical issues in regard to animal welfare. In this article, the authors apply the '3Rs' principles of humane experimental technique (replacement, reduction and refinement) to hibernation research. They provide recommendations for hibernation researchers and suggest future directions for addressing issues specific to hibernation research. They discuss the use of appropriate behavioral and physiological monitoring procedures, the development of species-specific brain atlases for placement of brain probes, the provision of environmental enrichment and the management of studies involving pharmacological induction of torpor. Addressing these issues in hibernation research will lead to improvements in research outcomes and in welfare of hibernating species.
\end{abstract}

Hibernation is a stage of some animals' yearly cycle consisting of a series of torpor bouts ${ }^{1}$. Torpor is a physiological state characterized by a regulated reduction of metabolism, body temperature, physical and neural activity, and protein synthesis ${ }^{1,2}$. An animal's ability to rewarm from torpor without any exogenous source of heat demonstrates that torpor is a highly regulated phenomenon ${ }^{1,2}$. The whole-body metabolism and body temperature of the hibernator can be reduced to $1 \%$ of the resting metabolic rate and to $-3{ }^{\circ} \mathrm{C}$, respectively, as seen in the arctic ground squirrel ${ }^{3-5}$ (Fig. 1). Thus, torpor in hibernating mammals represents the nadir in mammalian metabolism and body temperature ${ }^{1,6}$. Torpor in seasonal hibernators differs from torpor in daily heterotherms in several ways (Table 1).

Understanding the physiological mechanisms regulating hibernation may contribute to the development of treatments for life-threatening conditions such as cardiac arrest, stroke, cerebral ischemia, sleep disorders and hemorrhagic shock ${ }^{1,7-11}$. Muscle atrophy and loss of bone density during prolonged convalescence or space flight may be reduced with a better understanding of cellular structural maintenance during hibernation ${ }^{2}$. The number of hibernation studies published annually has increased from $<5$ per year in the 1960s and 1970s to >40 per year in 2010 and 2011, according to search results for the key words 'hibernation' and 'torpor' in the PubMed database (Fig. 2). Researchers who use hibernating animals face unique challenges in maintaining the well-being of their study subjects. Here we identify and discuss some ethical considerations in hibernation research.

Correspondence should be addressed to T.R.J. (tjinka@alaska.edu).

COMPETING INTERESTS STATEMENT

The authors declare no competing financial interests. 


\section{RESPONSIBLE CONDUCT OF HIBERNATION RESEARCH}

The overall objectives of experiments on animals, including hibernators, should be the advancement of understanding of the animals' biology; the pursuit of knowledge that would help to ensure their persistence in the wild and in captivity as part of a functioning ecosystem; and the development of information to benefit public good or improve animal or human health. The use of animal models is a privilege, not a right ${ }^{12}$, and must follow stringent ethical guidelines for experimental procedures, species selection, research design and number of animals used ${ }^{13,14}$. Ethical animal research is guided by the principles of the 3Rs: replacement, reduction and refinement ${ }^{15}$.

\section{REPLACEMENT}

Replacement refers to the use of alternative, non-animal-based techniques instead of animal models to answer scientific questions ${ }^{16,17}$. To our best knowledge, there are no viable alternatives to hibernating mammals that mimic their complex, integrated metabolism and seasonal behavior. Therefore, replacement is not usually possible in hibernation research. The use of live hibernators as experimental models is justified when the research outcome increases physiological or biochemical understanding of hibernation or results in the development of therapeutics, thereby potentially reducing suffering in humans and other animals ${ }^{18-21}$.

\section{REDUCTION}

Reduction refers to the minimization of the number of animals used to obtain results. Various strategies can be used to reduce animal numbers, although researchers should bear in mind the number of animals that is required for the study results to be statistically significant. One reduction strategy is to maximize the information obtained from each animal used in order to limit subsequent use of additional animals. Laboratory personnel may choose to alert all researchers when animals are going to be euthanized so that they may request tissue samples. In this way, while one researcher may collect the liver, other researchers may use the kidneys, brain, serum or other components of the same animal. In addition, researchers may collect and store tissues that are beyond the primary focus of their studies. Such tissue banks can be used for several research purposes: to provide specimens needed for drug discovery and development, to allow for retrospective analyses and to enable future re-analysis of tissue if improved analytical techniques become available ${ }^{22}$. Experimental design can also contribute to reductions in animal numbers. A balanced crossover design ${ }^{6,23}$ can be used in which the same data are collected several times for each subject. In pharmacological experiments, a cross-over experimental design uses the same animals for drug and vehicle treatments, with the advantage that each animal can be used as its own control, reducing the total number of animals used.

\section{Monitoring of torpor}

Tissue banks in hibernation research must be accompanied by detailed records of hibernation, housing and other conditions that can help to establish the seasonal phenotype of the animal, as well as by detailed descriptions of how tissues were collected. Detailed 
hibernation records require daily monitoring of torpor, which is usually accomplished by placing wood shavings or saw dust on the animals' backs and then checking daily for any disturbance of the shavings ${ }^{6,24}$. Shavings left undisturbed indicate that the animal is hibernating, whereas disturbed shavings indicate that the animal has aroused and moved since it was last checked. Hibernation can also be monitored using telemetry. Major surgery is required to implant the intraperitoneal transmitters, but the data obtained show unequivocal patterns of hibernation ${ }^{6,25-28}$. If hibernating animals are housed at ambient temperatures of $\geq 20^{\circ} \mathrm{C}$, then transponders such as the IPTT-300 (Bio Medic Data Systems, city, state) can be used to monitor body temperature with a telemetry system (DAS-6000; Bio Medic Data Systems) ${ }^{29,30}$. These transponders can be implanted subcutaneously between the scapula without surgery but may not be reliable below $21.4{ }^{\circ} \mathrm{C}$ (ref. 30). Programmable abdominal dataloggers are increasingly used in field studies to monitor animal behavior. These collect data, continuously or at specific intervals, that can be downloaded after a prescribed time period ${ }^{31}$.

\section{REFINEMENT}

Refinement is the modification of experimental procedures to minimize pain and distress experienced by the animal and to enhance its well-being. In hibernation research, telemetry and open-flow respirometry are refined techniques for monitoring core body temperature and rate of oxygen consumption, respectively. Aspects of hibernation research that warrant further refinement include brain anatomy atlases, habitat and environmental conditions, and management of pharmacologically induced torpor.

\section{Brain anatomy atlases}

Infusion of drugs into specific areas of the brain is commonly done in hibernation research and requires chronic implantation of guide cannulae, which in turn requires an accurate brain atlas. Brain anatomy atlases are lacking for many wild-caught hibernating species. Instead, researchers rely on an established rodent atlas ${ }^{32-34}$ or euthanize some animals to determine the brain coordinates after the experiment is complete, a deviation from the principles of the $3 \mathrm{Rs}^{15}$. Lack of an accurate brain atlas can lead to variations in cannula placement and experimental results. We suggest that brain anatomy atlases should be developed for hibernating species through careful post-experimental anatomical exploration of the brain and skull, with the objective of establishing coordinates for different structures of the brain in reference to the stereotaxically implanted needles. Researchers who use seasonal hibernators can establish coordinates as required for their experiments. Sharing these stereotaxic coordinates with the hibernation research community can help to establish coordinates for selected brain regions and, eventually, to develop an atlas. Magnetic resonance imaging and computed tomography can be used to develop a stereotaxic atlas of the brain ${ }^{35}$, but the expense and lack of universal availability of these techniques may limit their use.

\section{Habitat and environmental conditions}

Some hibernators, such as arctic ground squirrels, are colonial in their natural habitat ${ }^{36,37}$ but hibernate in individual burrows ${ }^{38}$. In captivity, they have traditionally been housed 
individually. Habitat influences stress levels in arctic ground squirrels ${ }^{36}$, and although some stress is expected in wild-caught species maintained in captivity ${ }^{39-41}$, the potential stress of individual housing could cause behavioral changes in reproduction and stress physiology ${ }^{36}$. Stress levels are reflected in fecal glucocorticoid production; hence, fecal monitoring of corticosteroids is a non-invasive method of evaluating stress in hibernating species ${ }^{42-44}$. Because stress can be mitigated by environmental enrichment, good animal care practice supports the provision of enrichment items such as plastic tubes, which can mimic burrows in an animal's natural habitat.

Although seasonal hibernation is a highly conserved phenology, the environmental conditions to which animals are exposed may affect their hibernation. Latitude can influence hibernation and torpor energetics ${ }^{45-48}$. Woodchucks in northern latitudes hibernate longer than their conspecifics in southern latitudes, and the length of torpor bouts varies with latitude ${ }^{47}$. As latitude increases, the length of the interbout arousal period decreases and the length of torpor bouts and the number of arousals increase. In bats, which are non-seasonal hibernators, the duration of torpor bouts is shorter in tropical populations than in subtropical ones, and the duration of torpor bouts is negatively correlated with the ambient temperature ${ }^{48}$. Therefore, care should be taken to mimic natural environmental variables such as ambient temperature and light:dark cycle when housing hibernators in captivity.

\section{Management of pharmacologically induced torpor}

In order to understand the mechanisms of hibernation, pharmacological studies are carried out in which drugs are used to induce a torpor-like state characterized by a suppression of all vital activities ${ }^{6,49}$. Such studies are ethically challenging because the animals' lives may be at risk during these procedures. In some cases, it may be unclear whether experimental subjects are entering torpor or hypothermia, especially if they show no signs of distress. Therefore, indicators such as oxygen consumption (metabolism) and body temperature must be monitored.

Comparison of the rate of cooling and the rate of oxygen consumption can be used to differentiate torpor from hypothermia ${ }^{6}$.

In all studies involving torpor, animals should be monitored closely for signs of distress that may require intervention. Studies should include an intervention protocol explaining how to respond to any unanticipated signs of distress. Researchers should request veterinarian guidance for supportive care or to administer euthanasia. Supportive care, as recommended by the veterinarian, should be the priority over euthanasia.

Hibernation researchers should bear in mind that different mechanisms regulate onset of and arousal from torpor. Some drugs may induce torpor but may not induce the full spectrum of mechanisms needed for spontaneous arousal. In addition, response to pharmacological induction of torpor may differ among species. When testing drugs for the first time on a novel species, a pilot study with a small sample size and escalating doses should be carried out, and animals should be closely monitored. Variations in response to pharmacological induction of torpor may arise from behavioral variations among hibernators. Facultative hibernators (e.g., hamsters) undergo torpor primed by environmental conditions, whereas 
seasonal hibernators (e.g., arctic ground squirrels) enter torpor driven by a circannual cycle. Pharmacological agents may induce torpor in one type of hibernator but not the other.

\section{CONCLUSIONS}

As the number of hibernation studies increases, it is important for the research community to appreciate the unique ethical considerations that they involve. Identifying and addressing ethical issues and animal welfare concerns enhances scientific integrity, improves the quality of research and promotes animal welfare ${ }^{39,50}$.

\section{Acknowledgments}

We thank Dr. Kelly L. Drew for her review and comments and the following agencies for funding: US Army Research Office (Grant W911NF-05-1-0280); US Army Medical Research and Material Command (Grant 05178001); National Institute of Neurological Disorders and Stroke (Grants NS041069-06 and R15NS070779); and Alaska Experimental Program to Stimulate Competitive Research.

\section{References}

1. Drew KL, et al. Central nervous system regulation of mammalian hibernation: implications for metabolic suppression and ischemia tolerance. J Neurochem. 2007; 102:1713-1726. [PubMed: 17555547]

2. Carey HV, Andrews MT, Martin SL. Mammalian hibernation: cellular and molecular responses to depressed metabolism and low temperature. Physiol Rev. 2003; 83:1153-1181. [PubMed: 14506303]

3. Geiser F. Metabolic rate and body temperature reduction during hibernation and daily torpor. Annu Rev Physiol. 2004; 66:239-274. [PubMed: 14977403]

4. Barnes BM. Freeze avoidance in a mammal: body temperatures below 0 degree $\mathrm{C}$ in an Arctic hibernator. Science. 1989; 244:1593-1595. [PubMed: 2740905]

5. Heldmaier G, Ortmann S, Elvert R. Natural hypometabolism during hibernation and daily torpor in mammals. Respir Physiol Neurobiol. 2004; 141:317-329. [PubMed: 15288602]

6. Jinka TR, Tøien $\varnothing$, Drew KL. Season primes the brain in an arctic hibernator to facilitate entrance into torpor mediated by adenosine A1 receptors. J Neurosci. 2011; 31:10752-10758. [PubMed: 21795527]

7. Dave KR, et al. Neuroprotection: lessons from hibernators. Comp Biochem Physiol B Biochem Mol Biol. 2012; 162:1-9. [PubMed: 22326449]

8. Drew, KL., et al. Hibernation: a natural model of tolerance to cerebral ischemia/reperfusion. In: Gidday, J.; Perez-Pinzon, MA.; Zhang, J., editors. Innate Tolerance in the CNS. Springer; New York: 2013. p. 37-50.

9. Drew, KL., et al. "Natural" tolerance in hibernators: Can we learn from physiological and preconditioning against ischemic or hypoxic brain injury? In: Schaller, BJ., editor. Ischemic Tolerance of the Brain. Research Signpost; Trivandrum, Kerala, India: 2009. p. 1-44.

10. Drew, KL.; Jinka, TR. The bioenergetic network of adenosine. In: Masino, S.; Boison, D., editors. Hibernation, Sleep, and Thermoregulation. Springer; New York: 2013. p. 253-272.

11. Rosania K. Inducing hibernation in the arctic ground squirrel. Lab Anim (NY). 2011; 40:262.

12. Macrina, FL. Scientific Integrity: Text and Cases in Responsible Conduct of Research. 3rd. ASM Press; Washington, DC: 2005.

13. Institute of Laboratory Animal Resources. Guide for the Care and Use of Laboratory Animals. National Academies Press; Washington, DC: 1996.

14. Silverman, J., et al. The IACUC Handbook. 2nd. CRC Press; Boca Raton, FL: 2007.

15. Russell, WMS.; Burch, RL. The Principles of Humane Experimental Technique. Methuen; London: 1959. 
16. Fabre I. Alternatives to animal testing. Bull Acad Natl Med. 2009; 193:1783-1791. [PubMed: 20669543]

17. Claude N. Reducing the use of laboratory animals. Bull Acad Natl Med. 2009; 193:1767-1772. [PubMed: 20669541]

18. Gibson WC. The cost of not doing medical research. J Am Med Assoc. 1980; 244:1817-1819.

19. Shanks, N. Animals and Science: A Guide to the Debates. ABC-CLIO; 2002. p. XXX

20. Frey RG. Justifying animal experimentation. Society. 2002; 39:37-47.

21. Singer, P. Animal Liberation. Avon Books; New York: 1990.

22. Hewitt RE. Biobanking: the foundation of personalized medicine. Curr Opin Oncol. 2011; 23:112119. [PubMed: 21076300]

23. Salkind, NJ., editor. Encyclopedia of Research Design. SAGE Publications; Thousand Oaks, CA: 2010.

24. Pengelley ET, Fisher KC. Rhythmical arousal from hibernation in the golden-mantled ground squirrel, Citellus lateralis tescorum. Can J Zool. 1961; 39:105-120.

25. Jinka TR, Rasley BT, Drew KL. Inhibition of NMDA-type glutamate receptors induces arousal from torpor in hibernating arctic ground squirrels (Urocitellus parryii). J Neurochem. 2012; 122:934-940. [PubMed: 22697356]

26. Karpovich SA, et al. Energetics of arousal episodes in hibernating arctic ground squirrels. J Comp Physiol B. 2009; 179:691-700. [PubMed: 19277682]

27. $\varnothing$, Tøien, et al. Hibernation in black bears: independence of metabolic suppression from body temperature. Science. 2011; 331:906-909. [PubMed: 21330544]

28. Jinka, TR., et al. Potential mechanisms of metabolic suppression downstream of central a1ar activation during onset of torpor. In: Ruf, T., et al., editors. Living in a Seasonal World: Thermoregulatory and Metabolic Adaptations. Springer; Heidelberg: 2012. p. 363-376.

29. Jinka TR, et al. Altered thermoregulation via sensitization of A1 adenosine receptors in dietaryrestricted rats. Psychopharmacol (Berl). 2010; 209:217-224.

30. Wacker CB, Rojas DA, Geiser F. The use of small subcutaneous transponders for quantifying thermal biology and torpor in small mammals. J Thermal Biol. 2012; 37:250-254.

31. Williams CT, et al. Data logging of body temperatures provides precise information on phenology of reproductive events in a free-living Arctic hibernator. J Comp Physiol B. 2011; 181:1101-1109. [PubMed: 21691770]

32. Pellegrino, LJ.; Pellegrino, AS.; Cushman, AJ. A Stereotaxic Atlas of the Rat Brain. 2nd. Plenum; New York: 1979.

33. Paxinos, G.; Watson, C. The Rat Brain: In Stereotaxic Coordinates. 2nd. Academic; 1986. p. XXX

34. Shirley, JR., et al. A Stereotaxic Atlas of the Brain of the 13-line Ground Squirrel (Citellus tridecemlineatus). Edgewood, MTL., editor. Arsenal; 1966. p. XXX

35. Aggarwal M, et al. Magnetic resonance imaging and micro-computed tomography combined atlas of developing and adult mouse brains for stereotaxic surgery. Neuroscience. 2009; 162:1339-1350. [PubMed: 19490934]

36. Hik D, McColl SC Jr, Boonstra R. Why are Arctic ground squirrels more stressed in the boreal forest than in alpine meadows? Ecoscience. 2001; 8:275-288.

37. Carl EA. Population control in arctic ground squirrels. Ecology. 1971; 52:395-413.

38. Buck CL, Barnes B. Temperatures of hibernacula and changes in body composition of arctic ground squirrels over winter. J Mammal. 1999; 80:1264-1276.

39. Merriman DK, et al. Current practices in a captive breeding colony of 13-lined ground squirrels (Ictidomys tridecemlineatus). Lab Anim (NY). 2012; 41:315-325. [PubMed: 23079915]

40. Wasser SK, et al. A generalized fecal glucocorticoid assay for use in a diverse array of nondomestic mammalian and avian species. Gen Comp Endocrinol. 2000; 120:260-275. [PubMed: 11121291]

41. Vaughan DK, et al. Capture, care, and captive breeding of 13-lined ground squirrels, Spermophilus tridecemlineatus. Lab Anim (NY). 2006; 35:33-40.

42. Keay JM, et al. Fecal glucocorticoids and their metabolites as indicators of stress in various mammalian species: A literature review. J Zoo Wildlife Med. 2006; 37:234-244. 
43. Jurke MH, et al. Monitoring hormones in urine and feces of captive bonobos (Pan paniscus). Primates. 2000; 41:311-319.

44. Peel AJ, et al. Non-invasive fecal hormone analysis and behavioral observations for monitoring stress responses in captive western lowland gorillas (Gorilla gorilla gorilla). Zoo Biol. 2005; 24:431-445.

45. Geiser F, Ferguson C. Intraspecific differences in behaviour and physiology: effects of captive breeding on patterns of torpor in feathertail gliders. J Comp Physiol B. 2001; 171:569-576. [PubMed: 11686615]

46. Fenn AM, Zervanos SM, Florant GL. Energetic relationships between field and laboratory woodchucks (Marmota monax) along a latitudinal gradient. Ethol Ecol Evol. 2009; 21:299-315.

47. Zervanos SM, et al. Latitudinal differences in the hibernation characteristics of woodchucks (Marmota monax). Physiol Biochem Zool. 2010; 83:135-141. [PubMed: 19958172]

48. Stawski, C. Comparision of variables of torpor between populations of a hibernating subtropical/ tropical bat at different latitudes. In: Ruf, T., et al., editors. Living in a Seasonal World: Thermoregulatory and Metabolic Adaptations. Springer; Heidelberg: 2012. p. 99-108.

49. Shintani M, et al. Characterization of N(6)-cyclohexyladenosine-induced hypothermia in Syrian hamsters. J Pharmacol Sci. 2005; 97:451-454. [PubMed: 15764835]

50. Jinka, TR. Natural protection against cardiac arrhythmias during hibernation: significance of adenosine. In: Breijo-Marquez, FR., editor. Cardiac Arrhythmias - New Considerations. InTech; 2012. p. 151-166.p. XXX

51. Geiser, F. Hibernation, daily torpor and estivation in mammals and birds: behavioral aspects. In: Breed, MD.; Moore, J., editors. Encyclopedia of Animal Behavior. Academic; Oxford: 2012. p. 77-83.

52. Swoap SJ, Weinshenker D. Norepinephrine controls both torpor initiation and emergence via distinct mechanisms in the mouse. PLoS One. 2008; 3:e4038. [PubMed: 19107190]

53. Geiser F, Ruf T. Hibernation versus daily torpor in mammals and birds: physiological variables and classification of torpor patterns. Physiol Zool. 1995; 68:935-966.

54. Buck CL, Barnes BM. Effects of ambient temperature on metabolic rate, respiratory quotient, and torpor in an arctic hibernator. Am J Physiol Regul Integr Comp Physiol. 2000; 279:R255-R262. [PubMed: 10896889]

55. Geiser, F. eLS. John Wiley \& Sons, Ltd; Chichester, UK: 2011. Hibernation: Endotherms. 

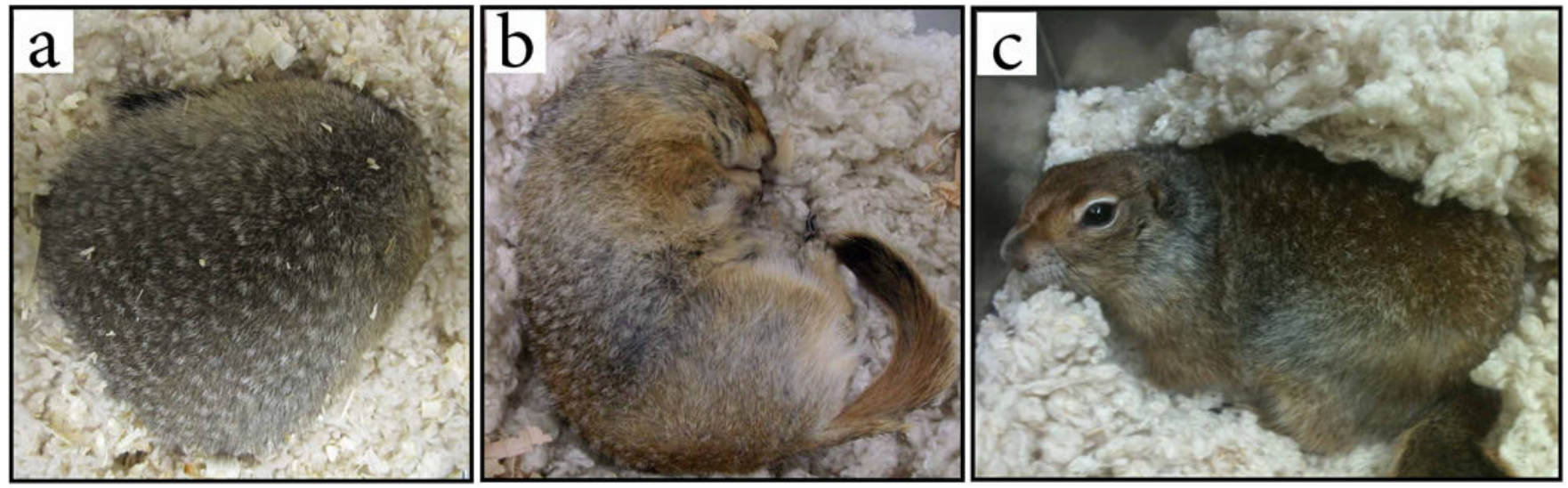

FIGURE 1.

Arctic ground squirrels. (a) Hibernating arctic ground squirrel (dorsal view). (b) Hibernating arctic ground squirrel (lateral view). (c) Non-hibernating arctic ground squirrel. 


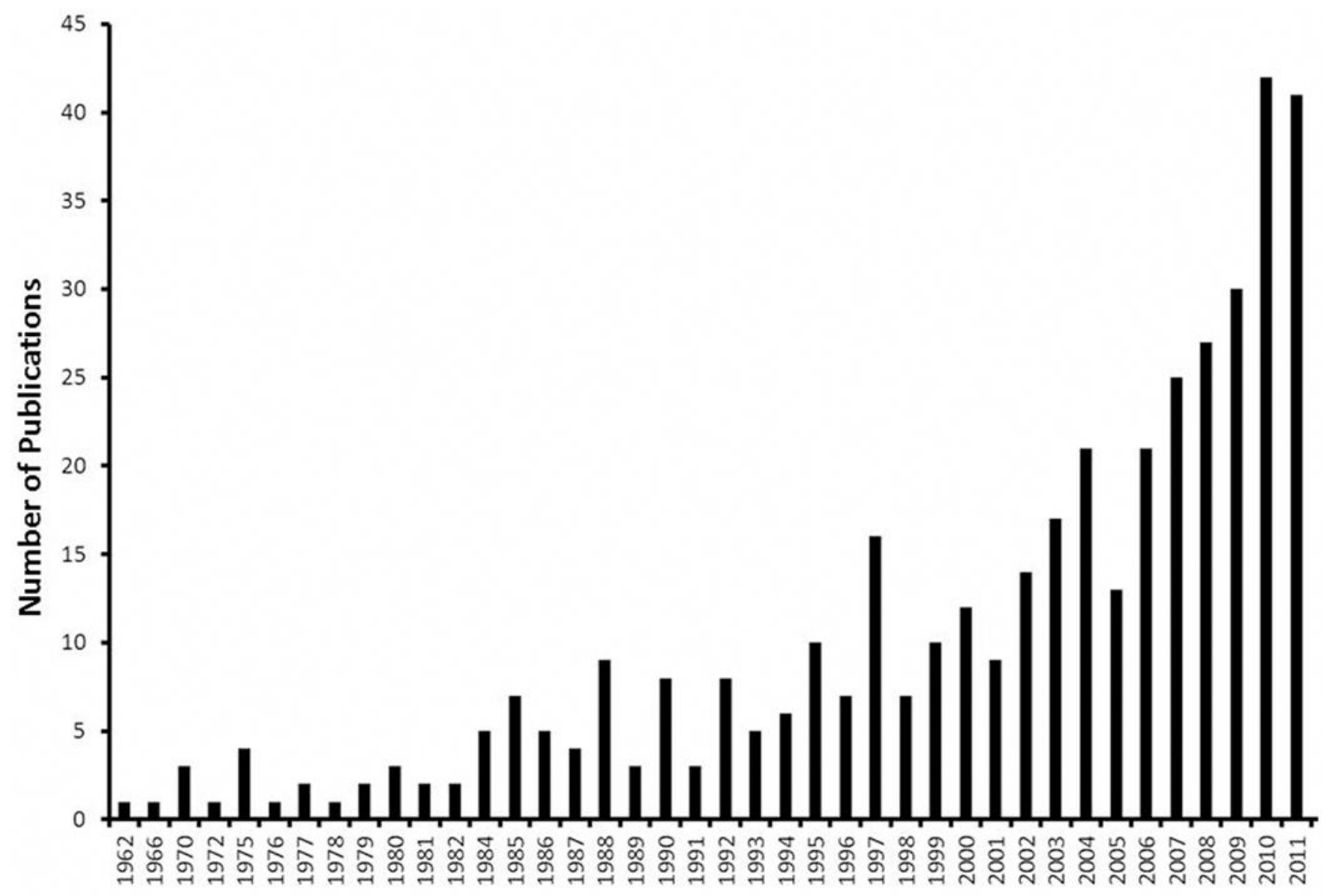

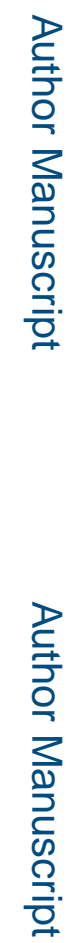

\section{Year of Publication}

FIGURE 2.

The number of hibernation studies published each year has increased from 1962 to 2011 . We searched the PubMed database for the key words 'hibernation' and 'torpor' and graphed the number of results for each year. 


\section{TABLE 1}

Differences in torpor of seasonal hibernators and of daily heterotherms

\begin{tabular}{|c|c|c|}
\hline & Seasonal hibernators & Daily heterotherms \\
\hline Seasonality & Yes $^{1,2,6}$ & $\mathrm{No}^{51}$ \\
\hline Duration of torpor bouts & Multiple days ${ }^{1}$ & Several hours (less than a day) $)^{52,53}$ \\
\hline Periodic arousals & Yes $^{1,2}$ & No, but torpor is interrupted by daily feeding ${ }^{51}$ \\
\hline Metabolism & $1-2 \%$ of basal metabolic rate (refs. 6,54$)$ & $30 \%$ of basal metabolic rate (refs. 51,55$)$ \\
\hline Body temperature & As low as $-3{ }^{\circ} \mathrm{C}$ (ref. 4 ) & $10-20^{\circ} \mathrm{C}$ (refs. 51,55$)$ \\
\hline Body mass & $10-1,000 \mathrm{~g}$ (except for bears) $)^{51}$ & $5-100 \mathrm{~g}($ ref. 51) \\
\hline Energy source & $\begin{array}{l}\text { Stored fat and, occasionally, food stored in the } \\
\text { hibernaculum } \\
1,51,53\end{array}$ & Daily foraging and feeding ${ }^{51}$ \\
\hline
\end{tabular}

